\title{
Assessing Mental Health Status among Primary School Children
}

\author{
Lee Moi Ching \\ Faculty of Education, Universiti Teknologi Malaysia \\ 81300 Skudai, Johor Bahru, Malaysia. \\ Yeo Kee Jiar \\ Faculty of Education, Universiti Teknologi Malaysia \\ 81300 Skudai, Johor Bahru, Malaysia. \\ Hadijah Jaffri \\ Faculty of Education, Universiti Teknologi Malaysia \\ 81300 Skudai, Johor Bahru, Malaysia.
}

\begin{abstract}
Mental health is the way we think or feel about ourselves, what is going on around us, and how we cope with the stresses of life and challenges, and those affects our sense of wellbeing as well as our physical health. Mental health refers to the cognitive and behavioral wellbeing of oneself due to the awareness towards situational and environmental activities as well as coping mechanism that one adopts to overcome stress and life challenges. In general, it is important to have good mental health in order to have better quality of life. Good mental health is important in learning and life, to meet challenges in life. In the present study, the researcher examined the primary children's mental health status. A total of 123 children from five Chinese-medium National Type Schools in Johor, Malaysia participated in this study. Strengths and Difficulties Questionnaire (SDQ) was used to identify the mental health difficulties of children in Year Two and Year Three. The children's mental health statuses were evaluated by their class teachers, and 41 teachers involved in the evaluation. Semistructured interview were conducted after the SDQ. Three teachers were selected to be interviewed. From this study, it was found that many of the children are suspected to have high risk for mental health difficulties. The findings in this study showed that conduct problems are the most significant problems, followed by hyperactivity problems, emotional problems, and peer problems. Generally, the teachers aware the children's problems, and understood that social-emotional learning is the best way to enhance children's mental health wellbeing.
\end{abstract}

Keywords: Mental Health; Mental Health Status; Mental Health Wellbeing; Mental Health Difficulties; Social-Emotional Skills; Social-Emotional Learning (SEL)

\section{INTRODUCTION}

In this modern society, our children are facing countless situation and challenges that can have a negative impact on their development of social-emotional and academic and ultimately on their happiness in life. Mental health problems affect the individual child, family, school system and society as a whole. Grappling with issues such as abortion, civil liberties, the definition of marriage, affirmative action, are great challenges for us. Mental health issues, including school children are a serious concern, but the prevalence rate of mental health problems in children can often co-occur or go unnoticed. There is urgency and need to address in order to minimize the mental disorders occur (Azizan, Razali, \& Pillai, 2013). 
Children's mental health issue has received considerable concern and attention from world for several decades (Tran, 2007), as it is an important aspect of childhood development, and as an important component of school readiness. Mental health of children also can be view as a cornerstone of later development for individual children. WHO (2012) states, "there is no health without mental health", emphasizes the importance of mental health involves everyone. Mental health issues are not only associated with mental illness, but is something that we all need. The feeling of well-being, happiness, coping challenges abilities, to accept others, and to have a positive attitude towards oneself, are all in mental health issue (Malaysia Mental Health Association MMHA, 2008). Mental health of children is the social and emotional well-being of children, encompasses the social, emotional and cognitive domains of development, and implies the well-being of children. The basis to mental health is the maturity in socialemotional domains. Mental health thus impacts learning, memory, motivation, critical thinking, behavior and academic performance. Healthy emotion regulation is a cornerstone of mental health and adjustment, whereas unhealthy emotion regulation lies at the core of many mental disorders (Vingerhoets, Nyklicek, \& Denollet, 2008).

Good mental health is important in learning and life, to meet challenges in life. In contrast, mental health problem may affect anyone at any age, and may significantly impair one's ability to form daily activities. According to Zivin, Eisenberg, Gollust and Golberstein (2009), the number of cases related to mental health problems among students is increasing every year worldwide. WHO (2012) estimated that around 450 million peoples suffer from mental health problem or illness with one in four families have at least one member with a mental health problem at any point in time.

Children who are suffering emotional distress or mental health difficulties find themselves difficult in learning, and give the impression of stuck or dumb in their difficulties and learning. The problems have major influence on children's families, schools and society. Children with mental health difficulties are less productive in educational and occupational settings, higher rates of mental illness, incarceration, family strife, and unemployment or underemployment (Rudolph \& Asher, 2000).

Give attention to children and adolescents who experience mental health problems is important to eliminate the social stigma of mental illness (Malaysia Mental Health Association MMHA, 2008). Early identification of children at risk for mental health problems is a key step in establishing preventive intervention programs. If children at risk do not receive early intervention and appropriate care, mental health problems in children may become crystallized patterns of behavior by age eight (Eron, 1990), beginning a trajectory of escalating academic problems, school dropout, drug abuse, depression, juvenile delinquency, antisocial behavior and violence in adolescence and adulthood (Snyder, 2001). Thus, it is urgent and necessary to gain awareness about issues related to mental health (MMHA, 2008). In view of this, the current proposed research intends to examine the status of mental health on children.

\section{BACKGROUND OF STUDY}

Mental health issues, including school children are a serious concern, but the prevalence of mental health problems in children can often co-occur or go unnoticed. Mental health issues are now a serious issue and the related problems in Malaysia are alarming. According to National Health and Morbidity Survey (2011), 12 percent of Malaysians with age 18 to 60 are suffering with some forms of mental illness, and the suicide rate increased from eight in the 1980 s to nowadays nine to 12 persons for every 100,000 population. Besides, adolescence and 

228-241.

children with age 15 and below showed mental health problems rose to 20 percent in year 2011. Tragedies occur due to mental health issues are tremendous and are not a new topic to Malaysia, but our society remained apathetic towards the problem. The articles reported about the tragedies caused by mental health problems such as commit suicide, crimes, and many others numerous tragedies are being published on media. The phenomenon is worrying. However the aspects of promotion, prevention and intervention of mental health related issues had lagged behind, as the actions taken against these problems should be geared up and widen to be more comprehensive. Mental health difficulties or problems among school children are a matter of serious concern, and it needs to be addressed urgently to minimize the mental disorders such as psychosis, depression and suicide.

Besides, mental health difficulties or problems can cause discipline problems in schools. Physical symptoms (e.g.: behavior problem) are a manifestation of psychological difficulties. Discipline problem is a common phenomenon in every school in Malaysia. Students with mental health difficulties at certain level are those who lack of skills to cope with their life challenges. With the absence of social-emotional competencies and emotional literacy, when the students are facing challenges in life, they will involve in various types of serious breaches of school policy and negative activities, such as bullying, truancy, gangsterism, vandalism, juvenile delinquency, pornography, drug use and the list will go on and on.

In Minister of Education's 2013 report, a total of 107,191 students were caught for indiscipline in 2012 , included truancy $(17,343$, or $16.18 \%)$, smoking (14298, or $13.34 \%)$, personal neatness (13926, or $12.99 \%)$, time wasting $(10403$, or $9.71 \%)$, misbehavior $(9926$, or $9.26 \%)$, bullying (4159, or $3.88 \%)$, pornography (3778, or $3.52 \%)$, vandalism (3630, or $3.39 \%)$, crime and delinquency (1432, or $13.36 \%$ ), and so forth, and comprised of 26.91 percent from primary schools. Delinquency $(20.70 \%)$ and truancy $(20.58 \%)$ showed the highest rates among the disciplinary problems of primary school children.

Meanwhile, National Mental Health Registry (NMHR) stated that public awareness about mental health issues is unsatisfied. Thus, $\mathrm{MOH}$ starts to put more concerted efforts to enhance inter-sectoral collaboration between related agencies, for instance, social welfare, education and labours, careers, non-government organizations (NGOs) and the community at large (Psychiatric and Mental Health Services Operational Policy, 2011). In year 2010, MOH has set up the Mental Health Promotion Advisory Council to enhance activities of mental health promotion between governments, NGOs, and the community. The council was set up in line with the efforts of government to overcome mental health problems, which are becoming more and more serious in the society. MOH has embarked on some mental health activities such as healthy lifestyle campaign, World Mental Health Day and mental health promotions activities in schools (e.g.: Kelab Doktor Muda, PROSTAR). Approach will be directed at different range of settings including families, schools, workplace and the communities.

According to Deputy Minister of Health, YB Dato' Seri Dr. Hilmi Bin Haji Yahaya mentioned that $\mathrm{MOH}$ promote a social mental health plan, aimed to assess the state of mental health of public. $\mathrm{MOH}$ is cooperating with Ministry of Education (MOE) to implement Healthy Mind Program (Program Minda Sihat) in schools. There are 151 secondary schools join in this program (Chinapress, 2013, July 23). The program is conducted to determine the state of mental health of secondary school students by conducting mental health screening on symptoms of stress, anxiety and depression. The students who are detected to have severe symptoms of stress, anxiety or depression, appropriate interventions will be given. 
The Healthy Mind Program is a good initiative by the MOH to assess students' mental health states as many health problems may pass unnoticed in schools. It is also aimed to promote mental health among secondary school students in facing any life challenges. But prevention should be started in early stage of children, and there is a need to develop a well comprehensive plan in promoting the prevention and early intervention program from preschool, continues through to tertiary education. Lack of prevention and early intervention for early stage of children, they might lack of social-emotional skills to cope with their problems. Thus, their problems will bring to secondary school and following by adult life and have an impact in their working, marriage and other important parts in their life.

Besides, MOE implements some strategies in education system to promote mental health wellbeing for students. One of the strategies is to integrate social and emotional elements into the curriculum through Moral Education ("Pendidikan Moral") and Health Education subjects ("Pendidikan Kesihatan"). But the implementation of this is still far from satisfactory due to the implementation plan is not well design, there is no real implementation and the teachers do not receive any training regarding social and emotional skills to teach. Some co-curricular activities such as exhibitions, seminars, and quizzes which contribute to mental health promotion also be held involving school clubs and Parent-Teacher Association (PTAs).

Children who lack of appropriate social skills and emotion management are self-doubt, low self esteem and sadness as they are unable to fully attend to school's daily expectations. The most common problems are anxiety, followed by disruptive behavior and mood problems (Power, 2003). Besides, failure to acquire adequate social and competency skills are associated with many negative outcomes, such as higher rates of mental illness, incarceration, family strife, and unemployed or underemployment. When the children with symptoms of social-emotional problems are left behind without giving proper helps, they might develop to at risk for mental health problems or mental health difficulties and affect their lives.

However, the tendency for discussions and research on mental health used to focus mainly on mental illness, disorders, or problems, the attention of school policy makers has been directed primarily to concerns about emotional disturbance, violence, and substance abuse, with a concomitant deemphasis on the school's role in the positive development of social and emotional functioning (Adelman \& Taylor, 2006). However, mental health is just about wellbeing of a person, instead of the often misunderstood as mental illness. In Malaysia, the tendency for discussion and research on mental health was focused mainly on mental illness, disorders, or problems. Besides, research on social-emotional aspects in relation to mental health in Malaysia is focused on medical students rather than on the general students' population (Zaid, Chan \& Ho, 2007). This lack of information entails that no clear image or comprehensive understanding of the mental health status among Malaysian children is available. This indicated the gap as lack of research on this arena. Hence, it was for this reason that this research was undertaken.

It is difficult to ascertain the prevalence of mental health problems in children, as the problems can often co-occur or go unnoticed. This makes it difficult to assess and intervene effectively. Many of the children with mental health problem do not receive appropriate services (Greenberg et al., 2003). The suffering of mental health problems are not only brings an impact on the individual child or family, but also affects school system and society as a whole. There are common news on media that the young persons in our country involved in bullying, violence, commit suicide and else emotional problems. And this phenomenon is alarming. What 
important qualities were missing in the youngsters who reacted so violently and impulsively when facing challenges?

But in Malaysia, this effort still lags behind. This study intends to start this effort from primary school and with a hope to extend to more systematic approach. Besides, the researcher would like to raise the attention of $\mathrm{MOH}$ and MOE in this effort, to understand and enhance the students' inner part. This study will enable government and educators to gauge the actual state of mental health among students, and decide on the best course of action to address mental health issues in schools. In sum, in helping children to successfully develop mental health wellbeing, and lead to success in school and adult life, thus, it is urging to understand their mental health state, the cause affect mental health issues, and how to help them to live with healthy mental health. Effective mental health promotion, prevention and early intervention strategies play a key role in improving mental health in the country and that reducing the prevalence and impact of mental health problem or illness.

\section{PURPOSE OF STUDY}

Parallel to the explanation above, following by understand the importance of mental health, attention should be paid to children, in order to identify and marginalized children to integrate them into the education process and provide the mental health promotion, prevention and intervention programs. Thus, the purpose of this study is to identify early sign of mental health difficulties, by investigating the current level of mental health status in Year Two and Year Three children. This study was conducted to have better understand for the current phenomena of the children, in order to gain insight on the needs of children, and as the basis for the further research to produce the contents and sequences for the design and development of the social-emotional learning intervention.

The research questions that drove this study were as follow:

1. What is the level of mental health difficulties among the Year Two and Year Three children?

2. What are the developmental issues such as internalizing problems and externalizing problems that negatively influence students' learning and behavior?

3. What are the impacts on students' life and school?

4. What are the possible causes of students' problems?

5. In what way effective to enhance students' mental health wellbeing?

6. Which components of mental health are critically important for students to improve?

\section{Participants Quantitative}

A total of 123 children from five Chinese medium national type primary schools located in suburban area in Johor participated in this study. The children were made up of slightly more females ( $n=68,55.3 \%)$ compared to males $(n=55,44.7 \%)$. Three children from each Year Two and Year Three classrooms were randomly selected by the class teachers. The mean age for the children is 8.5 years old. Class teachers $(\mathrm{N}=41)$ from determined Year Two and Year Three classes were recruited to complete the mental health difficulties test of children.

\section{Qualitative}

Three teachers were recruited amongst the teachers involved in quantitative data collection to participate in the semi-structured interview. Two female teachers and one male teacher from 
the three participated schools involved. They were teaching in Year Two and Year Three with more than five years teaching experiences.

\section{Research Design}

Quantitative and qualitative approaches were employed to fulfill the purpose of this preliminary study. For quantitative part, the mental health difficulties test namely Strengths and Difficulties Questionnaire (SDQ) was used to identify the mental health difficulties of children in Year Two and Year Three. The SDQ were followed up by qualitative part namely semi-structured interviews with three teachers. The semi-structured interview was conducted to have in depth information of pertinent issues that arose from the quantitative results and this enabled the researcher to understand more for children's mental health status.

\section{Instrument}

\section{Quantitative: Strengths and Difficulties Questionnaire (SDQ)}

The instrument namely "Strengths and Difficulties Questionnaire (SDQ)" teacher-informant report version (Goodman, 1997) was used in this study to measure the children's mental health difficulties. It contains 25 items. SDQ is well-established instrument, thus the validity and reliability are ensured. The researcher adopted SDQ in this study, no modification was allowed by the publisher. Double-sided versions with an impact supplement were conducted in this study.

The SDQ is a broad behavioural screening profile of children's emotional symptoms, conduct problems, hyperactivity/inattention, peer problems, and prosocial behaviour. The first four of these domains (emotional symptoms, conduct problems, hyperactivity/inattention and peer problems) can be combined in order to generate an index of mental health difficulties (Goodman, Lamping, \& Ploubidis, 2010). In general population samples, it may be better to use an alternative three-subscale division of the SDQ into "internalizing problems" (emotional + peer symptoms, ten items), "externalizing problems" (conduct + hyperactivity symptoms, ten items), and the prosocial items (five items) (Goodman et al., 2010).

In this study, to measure the mental health difficulties for children, only the four domains (emotional symptoms, hyperactivity/inattention, conduct problems, and peer problems) were used and combined to generate the index for mental health difficulties, and prosocial behaviour domain was eliminated from the index generation.

Participants receive a score for each domain of the SDQ in addition to an overall difficulties score that represent their total score across the four domains (emotional symptoms, hyperactivity/inattention, conduct problems, and peer problems). Participants receive a total difficulties scores ranging from 0 to 40, and each domain scores range from 0 to 10 . In both cases, a higher score indicates increased difficulties (with the exception of the prosocial behaviour domain, in which a higher score is indicative of increased strengths). As a broad indication, total difficulties scores of more than 13 for teacher version, are considered to be 'borderline/abnormal', and thus a possible cause for concern, as it is an indicative of possible mental health disorder(s).

The SDQ has strong psychometric properties, including excellent discriminative as it distinguishes clearly between psychiatric and non-psychiatric samples, factorial validity (established and confirmed by factor analysis) and construct validity (it correlates strongly with the Rutter scales) (Goodman, 1997; Smedje, Broman, Hetta, \& von Knorring, 1999). 
Goodman (2001) investigated the reliability of the SDQ gathered data from a large nationwide sample of 10,438 British aged five to fifteen. Teachers, parents and pupils aged 11-15 completed the SDQ. The study judged reliability as satisfactory, reporting a Cronbach's alpha coefficient of .73, which is above the minimum value showing the items within the SDQ strongly correlate with each other (Brace, Kemp \& Snelgar, 2009). Other than has strong internal consistency, it also has test-retest stability (average coefficient of .62 over six months) and predictive validity (scores above the 90th percentile on the SDQ strongly predict independently diagnosed psychiatric disorders) (Goodman, 2001).

\section{Qualitative: Semi-structured Interview}

A semi-structured interview was conducted for the three teachers from the three of the five schools which participated in the quantitative data collection for children's mental health status as mentioned in Section 2.4.1. Interview permits to examine the natural behaviors of human beings (Sansone et al., 2004), and to collect qualitative data in order to obtain in depth of understanding about the findings. The interview examined qualitatively, for assessing children's mental health status including the internalizing and externalizing problems and the impacts of the difficulties in their life. The interview took about 30 minutes and consisted of a variety of questions eliciting teachers' perception on children's problems in schools. Examples of the interview questions included: What are the developmental issues such as internalizing problems and externalizing problems that negatively influence your students' learning and behavior? What are the impacts on students' life and school? What are the possible causes of your students' problems? In what way do you think effective to enhance students' mental health wellbeing? Which components of mental health are critically important for students to improve?

The instruments were listed in the Table 1 as follow.

Table 1. Instruments

\begin{tabular}{|c|c|c|c|}
\hline & Instrument/Measurement & Content of Measurement & Participants \\
\hline 1 & Quantitative: SDQ & Children's mental health status & $\begin{array}{l}41 \text { teachers } \\
* 5 \text { schools } \\
* 123 \text { children }\end{array}$ \\
\hline 2 & $\begin{array}{l}\text { Qualitative: } \\
\text { structured interview }\end{array}$ & Children's mental health status & $\begin{array}{l}3 \text { teachers } \\
* 3 \text { schools }\end{array}$ \\
\hline
\end{tabular}

\section{Procedure of Data Collection and Data Analysis}

A total of five schools involved. Following receipt of school principals' permissions, the SDQ teacher-informant report version was administered. The SDQ were distributed to the involved class teachers and they were briefed on the purpose of the research, general administration guidelines and confidentiality by the researcher. Class teachers rated on the basis of the children's behaviour over the last six months or this school year by using Chinese version teacher-informant-rated SDQ. The SDQ were collected after one week. The data collected from SDQ were analyzed by using "Statistics Package For Social Sciences" (SPSS) and were summarized using appropriate statistics based on the objectives of this study.

After the SDQ collection, the interview was conducted separately at different venue and time as the teachers were from three different suburban schools. The interview took about 30 minutes. The researcher administered the interview based on the prepared questions eliciting teachers' perception on children's problems in schools. Responses gathered from the teachers through the interviews were aggregated and categorized. The information was then coded into themes. 
The teachers were responsive to interviews. The following abbreviations were used to identify the source of a data extract in the discussion of categories: $\mathrm{T} 1=$ Teacher 1 ; $\mathrm{T} 2=$ Teacher 2 ; and $\mathrm{T} 3=$ Teacher 3 .

\section{RESULTS}

The findings are analyzed, organized and presented in this section.

\section{Quantitative Data}

In respond to Research Question 1 to understand the mental health status of children, SDQ was used to generate the results. In SDQ, only the four domains namely emotional symptoms, hyperactivity/inattention, conduct problems, and peer problems were used and combined to generate the index for mental health difficulties. Internalizing problems could be understood by combining the emotional symptoms (emotional distress such as stress, anxiety, depression and so forth) and peer problems (difficulties in getting along with other children). By combining the conduct problems scores (behavioural difficulties such as lie, cheating, fighting and etc) and hyperactivity scores (hyperactive and concentration difficulties), externalizing problems could be understood. The findings were generated and showed in Table 2.

Table 2. Frequency Distributions on Symptoms Scores

\begin{tabular}{lcccccc}
\hline & \multicolumn{2}{c}{ Normal } & \multicolumn{2}{c}{ Borderline } & \multicolumn{2}{c}{ Abnormal } \\
\cline { 2 - 7 } & $\mathbf{n}$ & $\mathbf{\%}$ & $\mathbf{n}$ & $\mathbf{\%}$ & $\mathbf{n}$ & $\mathbf{\%}$ \\
\hline Total Difficulties Score & 45 & 36.6 & 19 & 15.4 & 59 & 48.0 \\
& & & & & & \\
Internalizing Problems & & & & & & \\
Emotional Symptom Scale & 83 & 67.5 & 8 & 6.5 & 32 & 26.0 \\
Peer Problems Scale & 70 & 56.9 & 19 & 15.4 & 34 & 27.6 \\
& & & & & & \\
Externalizing Problems & & & & & & \\
Conduct Problem Scale & 61 & 49.6 & 16 & 13.0 & 46 & 37.4 \\
Hyperactivity Scale & 68 & 55.3 & 10 & 8.1 & 45 & 36.6 \\
\hline
\end{tabular}

According to the total difficulties score showed in Table 2, there are nearly $50 \%$ (48\%) of children from Year Two and Year Three in the abnormal band for the total difficulties scares, and this score can be used to identify likely "cases" with mental health difficulties. The children were suspected to have high risk for mental health difficulties. This phenomenon is critical and worried our society.

There were around $28 \%$ children in the abnormal band for internalizing problems, while nearly $38 \%$ of children were suspected to have high risk for externalizing problems. The data above showed that $26.0 \%$ of children with high risk for emotional distress problems and $27.6 \%$ with high risk for problems with getting along with peers, while $37.4 \%$ and $36.6 \%$ children were in the high risk band for behavioural difficulties and hyperactivity. The rates of externalizing problems were slightly higher than internalizing problems. Both showed surprising statistics and the problems are alarming.

The difficulties have some negative impacts on children's life. Table 3 showed that 17.1\% children have "quite a lot", and 4.9\% children have "a great deal" impacts in upset or distress them. According to the teachers, the difficulties have major impact for $25.2 \%$ children in their peer relationships. Meanwhile, the difficulties also interfere with the children's everyday life in classroom learning, with $18.7 \%$ and $10.6 \%$ children in "quite a lot" and "a great deal" level, 
respectively. This finding aligned with Tran (2007)'s claim that mental health difficulties affects the individual child or family, school and society as a whole.

Table 3. Impact Scores of SDQ

\begin{tabular}{lcccccc}
\hline & \multicolumn{2}{c}{$\begin{array}{c}\text { Not at } \\
\text { all/Only a } \\
\text { little }\end{array}$} & \multicolumn{2}{c}{ Quite a lot } & \multicolumn{2}{c}{ A great deal } \\
\cline { 2 - 7 } & $\mathbf{n}$ & $\mathbf{\%}$ & $\mathbf{n}$ & $\mathbf{\%}$ & $\mathbf{n}$ & $\mathbf{\%}$ \\
\hline Upset or distress the child & 96 & 78.0 & 21 & 17.1 & 6 & 4.9 \\
Interfere peer relationship & 92 & 74.8 & 18 & 14.6 & 13 & 10.6 \\
Interfere classroom learning & 87 & 70.7 & 23 & 18.7 & 13 & 10.6 \\
\hline
\end{tabular}

\section{Qualitative Data}

Research Question 2 to 5 were used in generating qualitative data. Responses gathered from the teachers through the interviews were qualitatively analyzed through the method of aggregated and categorized, following by coding into themes. Table 4 showed the teachers interviews responses themes. The results from the qualitative data were discussed as follow:

\section{Research Question 2: What are the developmental issues such as internalizing problems and externalizing problems that negatively influence your students' learning and behavior?}

Before the questions were being asked, the teachers were briefed to understand about the mental health difficulties which consist of internalizing and externalizing problems. The following extracts are typical of the dataset as a whole:

[T1]...The students have a lot of behavioral problems. They like fighting and argument, as they don't know how to control their anger.

[T2]...Nowadays, the students are more aggressive, impolite, and have poor peer relationships. There is no cohesion among students in my classroom, I am thinking whether I lack of the practices to build the cohesion. I also noticed some students have emotion problems.

[T3]...I wonder why many students can't concentrate in class. They like to disturb others. And some students always complain that they have stomachache and headache, and always absent from schooling.

All of the three teachers had the congruent opinions that the Year Two and Year Three students were having behavioral problems such as fighting, argument, teasing on peers especially those with different ethnic or special needs students. Fighting and argument are common practice in many schools due to poor anger management skills. Besides, some students stole. One of the teacher mentioned that there were some cases in her school that the students stole something from other classroom with a proper and organized plan. And some students like to lie and disturb others for certain purpose to fulfill their own desire or intended to avoid for punishment.

Other than behavioral problem (conduct symptoms), some students had regular bouts of depression and unstable emotion. Some refused to attend to school and complaint stomachache or headache in class. Many students had problems in social skills, as they did not know how to manage relationship with other, did not know how to make friends, and some 
liked to bully others. Some students were disliked by others and thus were isolated by others. Majority students had concentration problem. They could not pay attention in the class and liked to disturb others. Three teachers also mentioned that their classrooms were lack of rules, the environment in the classroom were poor, no cohesion among students and lack of sense of belonging to schools.

\section{Research Question 2: What are the impacts on students' life and school?}

When asked about the impacts of mental health difficulties on children's life, the three teachers acknowledged the inevitable influences.

[T1]...Children can't learn if they are sad or have any worries in their mind. It's not easy for them to deal with those uncomfortable feelings.

[T2]...Nowadays many children are not happy, their negative emotion will affect their peer relationship. They can't get along with others happily, and others will isolate them also. Beside, the children can't concentrate in their learning too.

[T3]...If the children have mental health difficulties or social-emotional problems, definitely will have great impact on their peer relationship, behavior and academic performance. And the children with mental health difficulties, they will have an impact on other children's learning too. Also, they create discipline problems in school and this is headache.

As a whole, the three teachers mentioned that the problems had major or minor impacts for students' learning capacity, classroom atmosphere, peer relationship, behavior and academic performance. As consequences, students could not perform well in academic, low self-esteem and discipline problems occurred.

\section{Research Question 3: What are the possible causes of students' problems?}

To understand the possible causes of students' problems is important. In terms of factors influencing the mental health wellbeing development of children, the three teachers have same opinion on this question. The following excerpts demonstrate:

[T1]...The parents are too busy with works. Both of the parents work in most of the families. Leave very little time for children.

[T2]...Parents problems. Education system problems. Social norms problems.

[T3]...Our social just do not emphasize on social-emotional (SE) skills leaning. Government directives and pressures, school management focus on academic performance only, and parents are too busy to take care of their children. Children spend their time with smart phone, iPad, television, and those high technology appliances.

According to the teachers' statements, family problems were the most possible causes of students' mental health difficulties. The parents nowadays were busy with their works, with very limited time for their children and did not have quality time for the children. Nursery, tuition centre or baby sitters were the substitutes for the parents. The teachers mentioned that most of the parents could hardly talk or listen to their children, let alone to teach their children about the SEL skills. As the children did not have attention and love from their parents and 
family, and without SEL skills to manage their emotion, so the children come with depression, anxiety or behavior problems.

Other than that, the three teachers claimed that the social culture focused on speed and flooded with high technology. The needs to be loved was neglected, and thus caused loneliness in inner part. The three teachers also mentioned about the education system is academic based and caused much stress for parents, schools and students. SEL is a missing piece in education syllabus.

Research Question 4: In what way do you think effective to enhance students' mental health wellbeing?

A variety of strategies were elicited by the teachers:

[T1]...Give appropriate training to the parents and teachers to teach the children some important skills to cope with the challenges in their life.

[T2]...Education is the most effective way. Teachers have to undergo some training to teach the children some important skills. Most of the teachers don't have SEL practice in classroom. I think this is a serious problem.

[T3]...I think programs which can teach SE skills are effective to help children.

In sum, in terms of the effective way to enhance children's mental health wellbeing, teaching children the important skills such as SE skill was a dominant theme. Students' mental health wellness can be enhanced through teaching them with the SE skills. Education is the best way to achieve this goal.

\section{Research Question 5: Which components of social-emotional skills are critically important for students to improve?}

This question is added in based on the responses in question 4. Since the teachers believed that SE skills are important in enhancing children's mental health wellbeing, the researcher would like to further understand which skills are the most urgently needed for children's development.

[T1]...Skills that enable them to control and manage their emotion, especially anger.

[T2]...I think problem solving skills are very important. But most of the children do not have this skill.

[T3]...Anger management, problem solving skills and social skills. Some children just have difficulties in getting along with other, or just enjoying in teasing others. They need to learn about understand for self and others' feelings.

From the responses from the three teachers, anger management, social skills and problem solving skills are critically important for the students. The students lacked of skills in problem solving skills, so they used to fight or run away when problems were there. Even very tiny problems, the students also did not know how to think and get a way to solve it. 
The interview supports the result generated in SDQ. In sum, consistent with the SDQ results, the interview implies that many participated children in Year Two and Year Three were the group with high risk for mental health difficulties, especially in conduct problems (behavioral problems), followed by hyperactivity symptoms, peer problems and emotional symptoms.

Table 4. Teachers Interview Responses Themes

\begin{tabular}{|c|c|c|}
\hline & Interview Questions & $\begin{array}{c}\text { Responses aggregated into common } \\
\text { themes }\end{array}$ \\
\hline 1 & $\begin{array}{l}\text { What are the developmental issues such as } \\
\text { internalizing problems and externalizing } \\
\text { problems that negatively influence your } \\
\text { students' learning and behavior? }\end{array}$ & 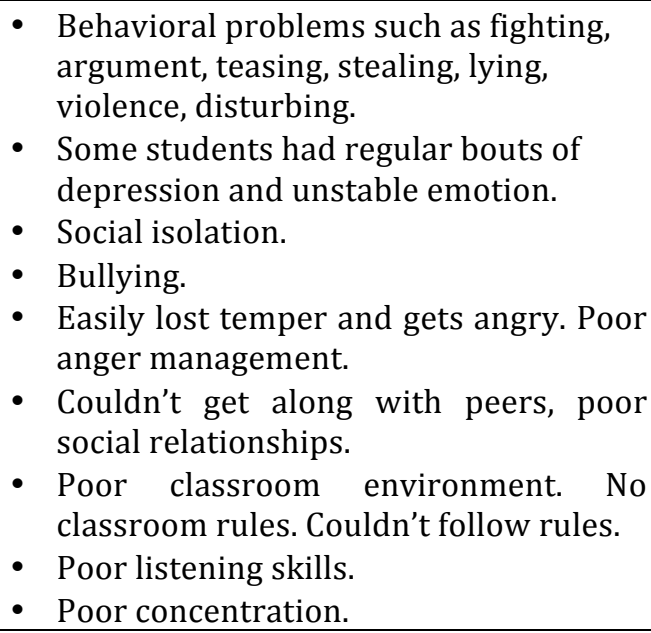 \\
\hline 2 & $\begin{array}{l}\text { What are the impacts on students' life and } \\
\text { school? }\end{array}$ & $\begin{array}{ll}\text { - } & \text { Learning capacity } \\
\text { - } & \text { Classroom atmosphere } \\
\text { - } & \text { Peer relationship } \\
\text { - } & \text { Behavior } \\
\text { - } & \text { Academic achievement }\end{array}$ \\
\hline 3 & $\begin{array}{l}\text { What are the possible causes of your } \\
\text { students' problems? }\end{array}$ & $\begin{array}{l}\text { - } \text { Family problem } \\
\text { - Social culture } \\
\text { - Education system with exam oriented } \\
\text { and academic based. } \\
\text { - Missing piece of social-emotional } \\
\text { learning in education syllabus. }\end{array}$ \\
\hline 4 & $\begin{array}{l}\text { In what way do you think effective to } \\
\text { enhance students' mental health wellness? }\end{array}$ & - Through education. \\
\hline 5 & $\begin{array}{l}\text { Which skills are critically important for } \\
\text { students to improve? }\end{array}$ & $\begin{array}{l}\text { - Anger management (Emotion } \\
\text { management) } \\
\text { - Social skills } \\
\text { - Problem solving skills }\end{array}$ \\
\hline
\end{tabular}

\section{DISCUSSION}

This study used mixed method, aims to examine the children's mental health status. The following discussions are based on the findings in this study.

From the results of this study, it is evident that many of the children are suspected to have high risk for mental health difficulties, and the teachers have some ideas of what constitutes mental health difficulties in children, and what are the effective ways to enhance children's mental health wellbeing.

The children showed a difference in their mental health and social-emotional development pace. The externalizing problems were more serious than the internalizing problems. But we have to bear in mind that this figure might not tell us the truth. It is difficult to ascertain the prevalence rate of mental health difficulties in children, as the problems can often co-occur or 

228-241.

go unnoticed, and especially the internalizing problems are always not as obvious as externalizing problems.

According to Zivin, Eisenberg, Gollust \&Golberstein (2009), the number of cases related to mental health problems among students are increasing every year worldwide. World Health Organization (WHO) reported that mental health issues are expected to increase by 15 percent by year 2020, and the group most at risk of experiencing this problem is young people.

The teachers seemed to demonstrate a high level of awareness of students' problems. One of the teachers also showed the awareness that teachers play a vital role in creating the positive classroom environment and thus build cohesion among students. The teacher further explained that the times and commitments for teachers to build relationship and caring connections with students are even very limited. Not only are the teachers are stress, the stress level of students rising too.

When asked about the impacts of mental health difficulties, the teachers have the same opinion that the learning will be affected. These comments aligned with some researches. Accordingly, research has shown that emotional skills are prerequisite to the thinking and learning skills that comprise the time-honored academic focus of education (Elias et al., 1997; Brendtro, Brokenleg, \& Van Bockern, 1990). For instance, "we know emotion is very important to educative process because it drives attention, which drives learning and memory" (Elias et al., 1997). Moreover, emotions impact perception, motivation, critical thinking and behavior (Izard, 2002; Mayer \& Salovey, 1997; Lazarus, 1991). In addition, Sousa (2000) and Humphrey et al. (2007) also revealed that there is relationship between the amygdale (the brain's emotional centre) and the frontal lobes which is the coordination of learning and higher level cognition takes place.

The teachers stated their beliefs in teaching children with SE skills can be the effective way in enhancing mental health wellbeing of children. Their beliefs are aligned with CASEL (2007)'s claim that the SE skills can be taught to diverse background of children by regular classroom teachers in any type of school. This is great to understand that the teachers showed their awareness for the importance of SEL in promoting children's mental health. This is aligned with the findings in the studies of Elder et al. (2013) and Vingerhoets et al. (2008) that socialemotional wellbeing is the cornerstone of mental health and impacts one's mental health wellbeing. Thus, with the absence of social-emotional competencies, the children might develop the risk for mental health difficulties or social-emotional problems. This is a key issue emerging from the data related to the mental health promotion for children in schools. This is a finding which warrants further attention in future research. Current government policy in Malaysia on promotion of mental health through social-emotional learning has shown an effort, but this efforts still lag behind, the SEL in curriculum is unsatisfied, and the SEL practices in schools is also far from satisfaction. This shows the gap in practice, and thus leads to further research.

In view of this, mental health education can be effectively practiced through schools with a systematic framework and approach. In regard to promoting mental health in schools, Merrell and Gueldner (2010) suggested that SEL programs may be conceptualized as efforts at the primary prevention level, noting, "mental health promotion is focused on a common goal - the well-being of children" (p. 804). SEL as a framework developed to address the schools' mental health challenges, can promote social-emotional skills acquisition through education, and also 
can be infused through school-based curricula or environment (Zins et al., 2004). SEL programs focus on meeting the mental health needs of children and adolescents by teaching emotional knowledge and skills to effectively manage their emotions, create meaningful relationships, and apply problem-solving skills. Therefore, at the primary prevention level, proponents of SEL programs emphasize weaving these core values and competencies of SEL curricula into the broader mission of the school. One way that SEL supporters conceptualize doing this is through teaching SEL programs in general education classrooms. By integrating SEL programs into general education, coordination of mental health programs increases through unifying SEL learning and academic learning (Merrell \& Gueldner, 2010).

The research presented in this study revealed the children's current problems and needs for further research in developing a universal SEL intervention program for every child to promote mental health. Followed by this study, the researcher will further design and develop a SEL intervention program based on the findings in this study.

\section{Reference}

Adelman, H. S., \& Taylor, L. (2006). School and community collaboration to promote a safe learning 8. environment. State Education Standard. Journal of the National Association of State Boards of Education, 7, 38-43.

Che Rozaniza Azizan, Asbah Razali, Rajalingam Pillai. Promoting Positive Mental Health among Students in Malaysia. Psychology and Behavioral Sciences. Vol. 2, No. 2, 2013, pp. 73-82.

Brace, N., Kemp, R., \& Snelgar, R. (2009). SPSS for Psychologists. Palgrave Macmillan.

Brendtro, L.K., Brokenleg, M., \& Van Bockern, S. (1990, republished 2004). Reclaiming Youth at Risk: Our Hope for the Future. Bloomington, IN: National Educational Service.

Collaborative for Academic Social and Emotional Learning (CASEL). (2007). Promoting Children's Success in School and Life. Chicago, IL: Author.

Chinapress, 2013, July 23. http://www.chinapress.com.my/node/442597

Elder, R., Evans, K., \& Nizette, D. (2013). Psychiatric and mental health nursing 3rd Edition. Elsevier, Australia.

Elias, M.J., Zins, J.E., Weissberg, R.P., Frey, K.S., Greenberg, M.T., Haynes, N.M., Kessler, R. Schwab-Stone, M.E., \& Shriver, T.P. (1997). Promoting social and emotional learning: Guidelines for educators. Alexandria, VA:

Association for Supervision and Curriculum.

Eron, L. D. (1990). Understanding aggression. Bulletin of the International Society for Research on Aggression, 12, 5-9.

Goodman, R. (2001). Psychometric properties of the Strenghts and Difficulties Questionnaire (SDQ). Journal of the American Academy of Child and Adolescent Psychiatry, 40, 1337-1345. 